\title{
Physical activity, body composition and bone density in ballet dancers
}

\author{
BY WOUTER D. VAN MARKEN LICHTENBELT ${ }^{1}$, MIKAEL FOGELHOLM², \\ RAMON OTTENHEIJM ${ }^{1}$ AND KLAAS R. WESTERTERP 1 \\ ${ }^{1}$ Department of Human Biology, University of Limburg, PO Box 616, 6200 MD Maastricht, \\ The Netherlands \\ ${ }^{2}$ UKK-Institute, PO Box 30, FIN-33500, Tampere, Finland
}

(Received 15 October 1994 -Revised 14 December 1994-Accepted 30 January 1995)

\begin{abstract}
The main purpose of the present study was to examine factors that affect bone mineral density (BMD) in female ballet dancers. Training history, $\mathrm{Ca}$ intake, body composition, total body BMD (TBMD) and site-specific BMD, and bone mineral content were described in twenty-four female ballet dancers (mean age 22.6 (SD 4.5) years). Training history was determined by questionnaires, Ca intake by $7 \mathrm{~d}$ dietary record, BMD and bone mineral content by dual-energy X-ray absorptiometry (DXA), total body water by ${ }^{2} \mathrm{H}$ dilution, extracellular water by bromide dilution, body fat by underwater weighing (UWW; twocomponent model), DXA, and the four-component (4C) model. Dancers had a significantly lower body mass index (BMI 18.9 (SD 1.0) $\mathrm{kg} / \mathrm{m}^{2}$ ) than controls $\left(21.3\right.$ (SD 1.9) $\mathrm{kg} / \mathrm{m}^{2}$ ), with significantly lower percentage body fat (17.4 (SD 3.9) v. 24.4 (SD 5.1)) but comparable fat-free mass. Mean TBMD (1.147 (SD 0.069$) \mathrm{g} / \mathrm{cm}^{2}$ ) was significantly higher $(6 \%)$ compared with that of a reference population. These high values could be attributed to the high BMD of legs and pelvis, the weight-bearing sites of the dancer's body. No relationship was found between age, start of ballet classes, period (years) of dancing, Ca intake, and BMD (total and site-specific). However, TBMD was positively related to BMI, and negatively related to the age of menarche. BMD of the legs was significantly related to daily period (h) of training. Depending on the method used the percentage body fat ranged from 16.4 (by DXA) to 18:3 by the $4 \mathrm{C}$ model. These differences were significantly related to the TBMD. Percentage body fat by the different methods was not significantly different, except for DXA and $4 C$ model. The present study showed that, despite the factors that have a negative effect on BMD, such as low body mass and late menarche, BMD in female ballet dancers was relatively high. These high values were probably caused by high levels of weight-bearing physical activity.
\end{abstract}

Bone mineral density: Dual-energy X-ray absorptiometry: Underwater weighing

Bone mass acquired during adolescence and early adulthood may be one of the most important determinants for the risk of osteoporosis later in life (Sowers \& Galuska, 1993). Bone mineral density (BMD) is determined by genetic and familial influences. Besides those, presumably positive factors affecting BMD are physical activity (Aloia et al. 1988; Kanders et al. 1988; Risser et al. 1990), total body and/or fat-free weight (Sowers et al. 1992 b), and dietary Ca intake (Halioua \& Anderson, 1989; Sowers \& Galuska, 1993). More likely negative factors are malnutrition (Rigotti et al. 1984; Biller et al. 1989), chronic strenuous exercise and hormonal disturbances (Suominen, 1993).

Ballet dancers are an interesting group for a study on factors affecting BMD, since ballet is a demanding discipline involving factors that could have both a positive (weight-bearing exercise) or negative (chronic strenous exercise, low dietary intake, low body mass, hormonal imbalance) effect on BMD. Studies in ballet dancers show conflicting results, ranging from low BMD to relatively high BMD (Warren et al. 1986a, b; Young et al. 1994). 
Weak bones mean increased risk of stress fractures, scoliosis (Warren et al. 1991) and severe postmenopausal osteoporosis. Therefore, we need to know more about factors increasing or decreasing BMD in ballet dancers. A distinct drawback in previous studies has been uncertain documentation of dancers' body composition. Most of the data on the body composition of ballet dancers have been obtained from skinfolds and underwater weighing (UWW; Hergenroeder et al. 1991). The classical two-component (2C) model for the measurement of body composition, however, is limited by assumptions regarding the constancy of composition of fat-free mass (FFM; Lohman, 1992). Due to changes in BMD and the hydration of the FFM these methods could give erroneous results.

In the present study we investigated physical activity, body composition, total body (TBMD) and site-specific BMD, and bone mineral content (BMC) of female ballet dancers. Next, we examined factors affecting BMD in the dancers. Finally we investigated the extent to which BMD affects body-composition assessment in ballet dancers.

\section{MATERIAL AND METHODS}

Subjects

Twenty-four female ballet dancers, recruited from Dutch ballet companies and ballet academies, participated in the present study. Contraceptive pills were not used by any of the subjects. The measurements on the dancers with regular (nine to fourteen cycles per year) menstruation were carried out during the first 2 weeks after menstruation. Twentynine female students, participating in another study on body-composition assessment, served as a control group. For comparison with BMD we used the age- and weightmatched reference values (from Germany reference population) provided by the manufacturer of the dual-energy X-ray bone densitometer (DXA; see p. 441). After being informed about the study, all subjects signed a written informed consent. The study was approved by the Medical Ethical Committee of the University of Limburg, Maastricht, The Netherlands.

\section{Questionnaires, intake, and energy expenditure}

All dancers were questioned about the age of menarche, number of menstruations over the last 12 months, and about training history (start of dancing, amount and type of training from childhood to present time). An oral interview was used to diagnose possible cases of anorexia nervosa and bulimia nervosa, according to the DSM-III diagnostic criteria (American Psychiatric Association, 1987). Ca and energy intakes were obtained from a $7 \mathrm{~d}$ dietary record. Participants were given oral and written instructions on how to fill in records with exact descriptions and amounts of all foods consumed. $\mathrm{Ca}$ and energy consumption was calculated by Becel ${ }^{\circledR}$ computer program, software version 1994 (Unilever Research Laboratorium, Vlaardingen, The Netherlands), using the Dutch Food Composition Table (Kommissie UCV, 1994). Resting energy expenditure (RMR) was measured in the morning, after a $10 \mathrm{~h}$ fast, with a ventilated-hood system (Servomex, Crowborough, Sussex) for $45 \mathrm{~min}$. Using the formula of Weir (1949), energy expenditure was calculated for the last two $15 \mathrm{~min}$ periods. The lower of these two values was used as RMR.

\section{Body composition}

Underwater weighing. Whole-body density $\left(\mathrm{D}_{\mathrm{b}}\right)$ was determined by UWW after an overnight fast. Lung volume was measured simultaneously with the He dilution technique using a spirometer (Volugraph 2000; Mijnhardt, Bunnik, The Netherlands). The mean of four to six measurements was used.

Deuterium dilution. Subjects received an orally administered dose of ${ }^{2} \mathrm{H}_{2} \mathrm{O}(0 \cdot 1 \mathrm{~g} / \mathrm{l}$ estimated total body water (TBW)). TBW was estimated initially from the formula of Deurenberg et al. (1991). The appropriate amount of ${ }^{2} \mathrm{H}_{2} \mathrm{O}(99.8 \%$; Akademie der 
Wissenschaften, Leipzig, Germany) was weighed out and diluted with tap water to 0.0751 for intake. ${ }^{2} \mathrm{H}_{2} \mathrm{O}$ enrichment in the body fluid was measured in urine. Before administration of the dose, background urine samples were taken. The dose was given at 08.30 hours, after an overnight fast. Urine samples were taken $4 \mathrm{~h}$ after dose administration from the second voiding (first voiding 11.00-11.30 hours). Isotope abundances in urine were determined in duplicate with an isotope-ratio mass spectrometer (Aqua Sira; VG Isogas, Middlewich, Cheshire). TBW was calculated as the ${ }^{2} \mathrm{H}$ dilution space divided by 1.04 , correcting for exchange of the ${ }^{2} \mathrm{H}$ label with non-aqueous $\mathrm{H}$ of body solids (Schoeller et al. 1980).

Bromide dilution. The extracellular water compartment was determined by bromide dilution. A known amount of $\mathrm{NaBr}(60 \mathrm{mg} \mathrm{Br} / 1$ estimated TBW; Ph.Eur., Genfarma bv, Maarssen, The Netherlands), was mixed with the ${ }^{2} \mathrm{H}_{2} \mathrm{O}$ solution and, thus, administered simultaneously with the ${ }^{2} \mathrm{H}_{2} \mathrm{O}$ dose. Venous blood samples were obtained before intake and $4 \mathrm{~h}$ after ingestion of bromide. Bromide concentration in serum ultrafiltrate was determined with HPLC (Miller et al. 1989). Corrected bromide space was calculated according to Miller et al. (1989).

Dual-energy $X$-ray absorptiometry. BMC and BMD were determined for the whole body and for the lumbar region (L2-L4) by a dual-energy X-ray absorptiometer (DPX-L; Lunar Corp., Madison, WI, USA; Mazess et al. 1990). We used the medium-scan mode with a resolution of $4.8 \times 9.6 \mathrm{~mm}$ (whole body) and $1.2 \times 1.2 \mathrm{~mm}$ (spine). BMC and BMD were calculated using Lunar software (Lunar Corporation, 1993). For the whole-body scan the subject lies in a supine position. During the spine scan of L2-L4 the position is also supine, but with the knees in an upright position. The results were compared with the Germany AP Spine and Total Body White Reference Population provided by the manufacturer.

Body-composition models. Percentage body fat was calculated by the classical $2 \mathrm{C}$ model using $D_{b}$ from UWW and the equations of Siri (1956):

$$
\text { percentage body fat }=\left(4.95 / D_{b}-4.50\right) \times 100 \text {. }
$$

The four-component (4C) model was based on four distinct chemical components within the body: fat, TBW, total BMC (TBMC), and remaining fat-free dry mass. Body composition was calculated by using combined measurements of body mass, TBW (by ${ }^{2} \mathrm{H}$ dilution), TBMC (by DXA) and $\mathrm{D}_{\mathrm{b}}$ (by UWW). Percentage body fat was according to the formula given by Lohman (1992):

percentage body fat $=$

$\left(2 \cdot 747 / \mathrm{D}_{\mathrm{b}}-0.714 \times \mathrm{TBW} /\right.$ body mass $+1.146 \times \mathrm{TBMC} /$ body mass -2.0503$) \times 100$,

(where $\mathrm{D}_{\mathrm{b}}$ is expressed in $\mathrm{g} / \mathrm{cm}$, TBW in litres, and body mass and TBMC in $\mathrm{kg}$ ).

\section{Statistical analyses}

Mann-Whitney U test was used to establish significance of any differences between dancers and controls. Pearson correlation coefficients were used to test relationships between differences in percentage body fat estimates of different methods/models and BMD. The bias and $95 \%$ confidence interval (CI) between the different methods were calculated according to the method described by Altman \& Bland (1983). Pearson correlation coefficients and stepwise-regression analyses were used to determine the relationships between supposed factors related to BMD and BMC. All values are expressed as means and standard deviations.

\section{RESULTS}

Subjects, training history and calcium intake

According to the DSM-III criteria (American Psychiatric Association, 1987), none of the dancers had anorexia nervosa or bulimia nervosa. Of the twenty-four dancers, seven had 
Table 1. Descriptive characteristics of female ballet dancers and controls* (Mean values and standard deviations and ranges)

\begin{tabular}{|c|c|c|c|c|c|c|c|}
\hline \multirow[b]{2}{*}{ Variable } & \multicolumn{3}{|c|}{ Dancers ( $n$ 24) } & \multicolumn{3}{|c|}{ Controls ( $n$ 29) } & \multirow{2}{*}{$\begin{array}{c}\text { Statistical significance } \\
\text { of difference } \\
\text { ( } t \text { test) }: P<\end{array}$} \\
\hline & Mean & SD & Range & Mean & SD & Range & \\
\hline Age (years) & $22 \cdot 6$ & $4 \cdot 5$ & $17-34$ & $21 \cdot 4$ & $1 \cdot 5$ & 19-27 & NS \\
\hline Height (m) & 1.67 & 0.56 & $1 \cdot 52-1.78$ & 1.69 & 0.54 & $1.58-1.80$ & NS \\
\hline Wt (kg) & $52 \cdot 4$ & $4 \cdot 6$ & $45 \cdot 7-64 \cdot 0$ & $60 \cdot 8$ & 60 & $49 \cdot 2-69 \cdot 9$ & 0.0001 \\
\hline BMI $\left(\mathrm{kg} / \mathrm{m}^{2}\right)$ & 18.9 & $1 \cdot 0$ & $16 \cdot 6-20 \cdot 8$ & $21 \cdot 3$ & 1.9 & $17 \cdot 5-24 \cdot 8$ & 0.0001 \\
\hline
\end{tabular}

* For details of subjects, see p. 440.

Table 2. Body composition of female ballet dancers and controls* (Mean values and standard deviations and ranges)

\begin{tabular}{|c|c|c|c|c|c|c|c|}
\hline \multirow[b]{2}{*}{ Variable } & \multicolumn{3}{|c|}{ Dancers ( $n$ 24) } & \multicolumn{3}{|c|}{ Controls ( $n$ 29) } & \multirow{2}{*}{$\begin{array}{c}\text { Statistical significance } \\
\text { of difference } \\
\text { ( } t \text { test }): P<\end{array}$} \\
\hline & Mean & SD & Range & Mean & SD & Range & \\
\hline $\mathrm{D}_{\mathrm{b}}(\mathbf{U W W})$ & 1.059 & 0.009 & $1.044-1.076$ & 1.042 & 0.011 & $1.024-1.061$ & $0-0001$ \\
\hline$\%$ BF (UWW) & $17 \cdot 4$ & 3.9 & $10 \cdot 0-24 \cdot 1$ & $24 \cdot 4$ & $5 \cdot 1$ & $15 \cdot 6-32 \cdot 8$ & 0.0001 \\
\hline FFM (UWW) & $43 \cdot 2$ & $3 \cdot 3$ & $38 \cdot 2-49 \cdot 7$ & $45 \cdot 4$ & $4 \cdot 6$ & $36 \cdot 1-56 \cdot 1$ & NS \\
\hline TBW $\left({ }^{2} \mathrm{H}_{2} \mathrm{O}\right) \dagger$ & $30 \cdot 4$ & $2 \cdot 9$ & $24 \cdot 8-36 \cdot 0$ & $32 \cdot 1$ & 3.0 & $26 \cdot 5-39 \cdot 9$ & 0.04 \\
\hline CBS (Br)t & $13 \cdot 8$ & $1 \cdot 2$ & $11 \cdot 2-16 \cdot 6$ & $14 \cdot 3$ & $1 \cdot 3$ & $10 \cdot 7-16 \cdot 6$ & NS \\
\hline CBS: TBW & 0.45 & 0.02 & $0.43-0.49$ & 0.45 & 0.03 & $0.40-0.51$ & NS \\
\hline TBW:FFM & 0.71 & 0.03 & $0.63-0.78$ & $0 \cdot 71$ & 0.02 & $0.67-0.76$ & NS \\
\hline
\end{tabular}

$\mathrm{D}_{\mathrm{b}}$, body density; \%BF, percentage body fat; FFM, fat-free mass; TBW, total body water; CBS, corrected bromide space; TBW, total body water; UWW, underwater weighing.

* For details of subjects, see p. 440 and Table 1.

$\uparrow$ Deuterium dilution method; for details, see pp. 440-441.

$\ddagger$ Bromide dilution method; for details, see p. 441 .

menstrual disorders (four cycles or less during the last year). Age of menarche ranged from 11 to 20 years, with an average of 14.3 (SD 2.2) years and a median of $14 \cdot 0$ years (90th percentile: $16 \cdot 2$ years). Present age minus age of menarche was $8 \cdot 3$ (range $0-21$ ) years. Present training hours were quite variable from 20 to $48 \mathrm{~h}$ per week. Start of ballet classes ranged from 2 to 18 (mean 7.3 (SD 6.5) years, while start of classes with more than $10 \mathrm{~h}$ per week training ranged from the age of 10 to 23 (mean 15.0 (SD 3.7)) years. There were no significant relationships between the present training hours, or start of classes, and the age of menarche. Also, no relationships were found when the three subjects that started ballet classes after the age of 10 years were excluded from analyses. Energy intake in the dancers was 6.5 (SD 2.4; range $3.0-9 \cdot 3$ ) MJ/d, Ca intake was 742 (SD 289; range $317-1336$ ) $\mathrm{mg} / \mathrm{d}$ and RMR was $5 \cdot 6(\mathrm{SD} 0.5) \mathrm{MJ} / \mathrm{d}$.

\section{Body composition}

Body fat and body water. There were no significant differences in body composition between eumenorrheic dancers and dancers with menstrual disorders (W. D. van Marken Lichtenbelt, M. Fogelholm, R. Ottenheijm \& K. R. Westerterp, unpublished results); therefore results from all dancers were pooled. Age and height were not significantly different between dancers and controls (Table 1). However, body mass and BMI (body 
mass / height ${ }^{2}$ ) were significantly lower in the dancers. These differences were reflected in the results on body composition (Table 2). $\mathrm{D}_{\mathrm{b}}$ was higher, and percentage body fat (by UWW) was significantly lower in the dancers. There was no difference in FFM between the two groups, indicating that the previously mentioned difference in body mass was due mainly to differences in body fat content. This was illustrated also by comparing FFM indices (FFM/height ${ }^{2}$ ) and fat mass indices (fat mass/height ${ }^{2}$; Westerterp et al. 1992). The average FFM index of dancers $\left(15.6(\mathrm{SD} 0.8) \mathrm{kg} / \mathrm{m}^{2}\right)$ was not significantly different from that of the controls $\left(15.9(\mathrm{SD} 1.0) \mathrm{kg} / \mathrm{m}^{2}\right)$, while the FM index was significantly lower in dancers (dancers 3.3 (SD 0.8), controls 5.4 (SD 1.4); $P<0.001$ unpaired $t$ test).

The body fluid status of the dancers and controls was similar. There were no differences between TBW and corrected bromide space, and between corrected bromide space:TBW and TBW:FFM (TBW by ${ }^{2} \mathrm{H}_{2} \mathrm{O}, \mathrm{FFM}$ by UWW). According to these calculations the hydration of the FFM was on average 71 (SD 3) \%.

Bone densities. Average total bone mineral densities (TBMD) were $1 \cdot 147 \mathrm{~g} / \mathrm{cm}^{2}$ (Table 3 ). TBMD in the dancers was significantly higher compared with an age- and weightmatched reference population ( $95 \% \mathrm{CI}>100 \%$ ). BMD of arms and head (not shown) were not significantly different from those of the reference population. The high TBMD was caused mainly by the high BMD of legs and pelvis.

\section{Factors affecting bone mineral density}

No relationships existed between BMD and age and/or Ca intake. TBMD was significantly related to BMI (Fig. 1), and negatively related to the age of menarche (Fig. 2). The age of menarche was in its turn negatively related to BMI $(R-0.48, P<0.05)$. Associations were found also with the BMD of different sites. BMD of L2-L4 was negatively related to the age of menarche, and BMD of legs, pelvis and arms were significantly related to BMI (Table 4). The start of training was not related to BMD. However, BMD of the legs was significantly related to the daily period $(\mathrm{h})$ of training.

Stepwise regressions between the independent variables BMI, age, age of menarche, age of start of classes, period (h) of training (HT), Ca intake, and menstrual disorders entered as a dichotomial variable and the dependent variables TBMD, $B M_{\text {legs }}, B M_{\text {arms }}$, $B M D_{\text {spine }}$, or $B M D_{\text {pelvis }}$ revealed that $B \mathrm{BD}_{\text {legs }}$ was significantly related to $\mathrm{BMI}$ and training period:

$$
\mathrm{BMD}_{\text {legs }}=0.069 \mathrm{BMI}+0.008 \text { training period }+0.121(R 0.63, P<0.05) \text {. }
$$

Because of the significant correlation between BMI and age of menarche, stepwise regressions were also carried out with the same variables, but without BMI, and also without age of menarche. This did not affect the results.

\section{Method comparison}

The different methods for determination of body fat revealed different results (Table 5). Mean percentage body fat ranged from 16.4 by DXA to 18.3 by the $4 \mathrm{C}$ method, and mean FFM values ranged from $42 \cdot 8$ (4C) to $43 \cdot 7$ (DXA). These differences were related to TBMD:

percentage body fat $(2 \mathrm{C})-$

percentage body fat $(4 \mathrm{C})=-15.23 \mathrm{TBMD}+16.60\left(R^{2} 0 \cdot 24, P<0 \cdot 02\right)$, percentage body fat (DXA)-

percentage body fat $(2 \mathrm{C})=29 \cdot 48 \mathrm{TBMD}-34.79\left(R^{2} 0.46, P<0.001\right)$, percentage body fat (DXA) -

$$
\text { percentage body fat }(4 C)=14.32 \text { TBMD }-18.29\left(R^{2} 0 \cdot 14, P<0.07\right) \text {, }
$$


Table 3. Total bone mineral density (TBMD), total bone mineral content $(T B M C)$ and spine (L2-L4) bone mineral density $(B M D)$ determined by dual-energy $X$-ray absorptiometry* for twenty-four female ballet dancers compared with an age-and weight-matched reference population $\dagger$

(Mean values and standard deviations and ranges)

\begin{tabular}{|c|c|c|c|c|c|c|c|}
\hline \multirow[b]{2}{*}{ Variable } & \multicolumn{3}{|c|}{ Dancers } & \multicolumn{3}{|c|}{$\begin{array}{l}\text { Percentage age- and weight- } \\
\text { matched } \\
\text { reference values }\end{array}$} & \multirow[b]{2}{*}{$95 \% \mathrm{CI}$ of the mean } \\
\hline & Mean & SD & Range & Mean & SD & Range & \\
\hline $\operatorname{TBMD}\left(\mathrm{g} / \mathrm{cm}^{2}\right)$ & $1 \cdot 147$ & 0.069 & $0 \cdot 988-1 \cdot 269$ & 106 & 6 & $91-119$ & $103-109$ \\
\hline TBMC $(\mathrm{kg})$ & $2 \cdot 429$ & $0 \cdot 248$ & $2 \cdot 041-3.023$ & - & - & - & - \\
\hline \multicolumn{8}{|l|}{$\operatorname{BMD}\left(\mathrm{g} / \mathrm{cm}^{2}\right)$ : } \\
\hline Arms & 0.820 & 0.055 & $0 \cdot 707-0.903$ & 100 & 7 & $86-111$ & $97-103$ \\
\hline Legs & 1.239 & $0 \cdot 103$ & $1 \cdot 028-1 \cdot 446$ & 113 & 8 & $93-132$ & $109-116$ \\
\hline Trunk & 0.933 & 0.068 & $0.770-1.047$ & 109 & 8 & $93-124$ & $105-112$ \\
\hline Pelvis & $1 \cdot 141$ & $0 \cdot 107$ & $0 \cdot 870-1 \cdot 310$ & 111 & 10 & $88-131$ & $107-115$ \\
\hline L2-L4 & $1 \cdot 223$ & $0 \cdot 119$ & $1.052-1.415$ & 107 & 10 & $92-125$ & $102-111$ \\
\hline
\end{tabular}

* For details of procedures, see p. 441.

$\dagger$ For details of subjects and reference population, see p. 440 and Table 1.

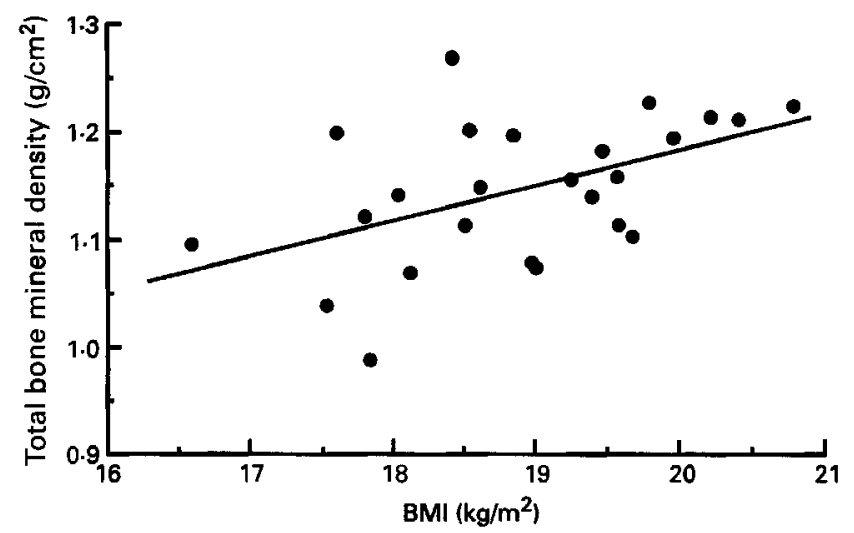

Fig. 1. Total bone mineral density (TBMD) in relation to BMI for twenty-four female ballet dancers. TBMD = $0.32 \times \mathrm{BMI}+0 \cdot 54, R 0 \cdot 49, P<0 \cdot 05)$. For details of subjects and procedures, see pp. $440-441$ and Table 1 .

with one outlier $(P<0.05$; Dixon, 1950). After removing the outlier:

percentage body fat (DXA)-

$$
\text { percentage body fat }(4 \mathrm{C})=17 \cdot 39 \mathrm{TBMD}-22 \cdot 21\left(R^{2} 0 \cdot 39, P<0 \cdot 002\right)
$$

Plots of the difference between percentage body fat by two methods/models against the average of both measurements (Altman \& Bland, 1983) showed no significant associations (Fig. 3). The differences between the methods were thus independent of the size of the variable. The mean differences between $2 \mathrm{C}$ and $4 \mathrm{C}$, and $\mathrm{DXA}$ and $2 \mathrm{C}$ were not significant from zero (Table 5), while the results from DXA were significantly smaller than those determined by the $4 \mathrm{C}$ model. 


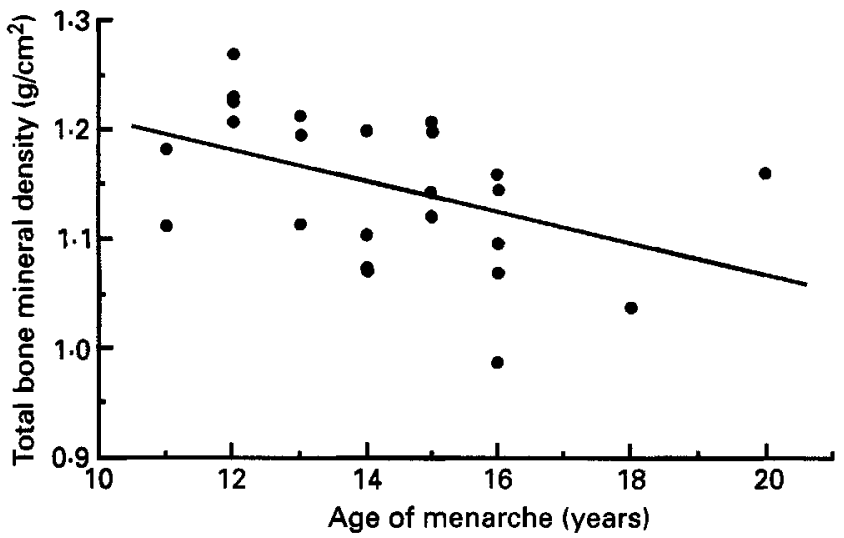

Fig. 2. Total bone mineral density (TBMD) in relation to the age of menarche (MENA) for twenty-four female ballet students. TBMD $=-0.014 \times$ MENA $+1.35 ; R 0.46, P<0.05$ ). For details of subjects and procedures, see pp. $440-441$ and Table 1.

\section{DISCUSSION \\ Body composition}

Body mass, BMI and percentage body fat were lower in dancers compared with controls, while the FFM and the FFM index were not significantly different between the two groups. This was in agreement with other recent studies comparing ballet dancers and controls (Karlsson et al. 1993; Young et al. 1994). The percentage body fat as determined by UWW $(17.4)$ was in close agreement with other results of studies using UWW: 16.4 (Clarkson et al. 1985), 16-17 (Kirkendall \& Calabrese, 1983). The dancers in the latter studies were on average younger than the dancers in the present study, explaining the somewhat lower percentage body fat. Only Hergenroeder et al. (1991) found much higher percentage body fat $(20 \cdot 1)$, but used total body electrical conductivity for body composition assessment.

The hydration of the FFM $(71 \%)$ was not significantly different from that of the controls. The value was within the generally accepted range of water content of 71-74\% in young adults (Lohman, 1992), and similar to the mean hydration found in male athletes (71.3; Withers et al. 1992). The extracellular water:TBW also was not significantly different between dancers and controls and similar to the ratio in normal subjects (Shizgal, 1983).

\section{Factors affecting bone mass density}

TBMD and BMD of different sites of measurement were significantly related to BMI. Sowers et al. (1992b) showed in a cross-sectional study that BMD was larger in highmuscle-high-fat and high-muscle-low-fat subgroups compared with low-muscle-high-fat and low-muscle-low-fat subgroups, indicating that BMI alone is not a determinant of BMD, but muscle mass has an independent effect. Indeed, in the present study the fat mass index was not related to TBMD $(P>0.05)$, but the association between FFM index and TBMD was significant $(P<0 \cdot 001)$. Muscle mass can be increased by physical activity or support of adipose tissue (Kanders et al. 1988). The ballet dancers belong to a highmuscle-low-fat group with relatively high BMD. Muscle mass in ballet dancers probably reflects physical activity.

Compared with the reference populations the ballet dancers had significantly higher TBMD values. It should be noted that we did not compare the dancers' BMD with an ageand BMI-matched control group, but with an age- and weight-matched reference 


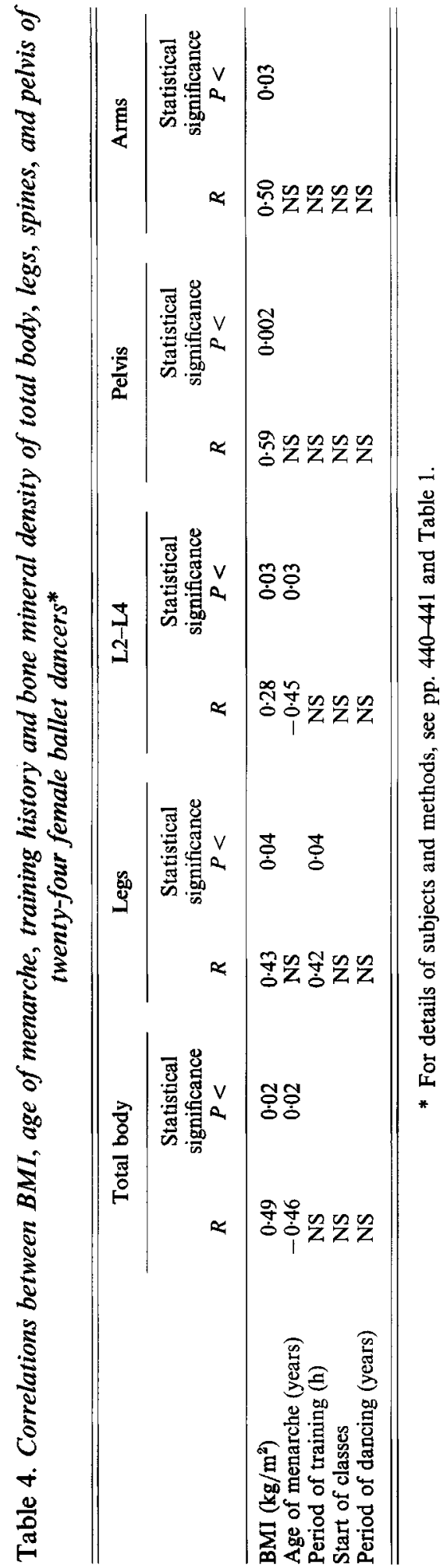


Table 5. Comparison of percentage body fat and fat-free mass (FFM) of twenty-four female ballet dancers $\dagger$ determined using the two-component model (2C), four-component model (4C) and dual-energy $X$-ray absorptiometry (DXA) methods

\begin{tabular}{|c|c|c|c|c|c|c|}
\hline \multirow[b]{2}{*}{ Method } & \multicolumn{3}{|c|}{ Percentage body fat } & \multicolumn{3}{|c|}{ FFM } \\
\hline & Mean & SD & Range & Mean & SD & Range \\
\hline $2 \mathrm{C}$ & $17 \cdot 4$ & 3.9 & $10 \cdot 0-24 \cdot 1$ & $43 \cdot 2$ & $3 \cdot 3$ & $38 \cdot 2-49 \cdot 7$ \\
\hline $4 \mathrm{C}$ & $18 \cdot 3$ & 3.8 & $9 \cdot 6-23 \cdot 8$ & 42.8 & 3.6 & $36 \cdot 6-49 \cdot 2$ \\
\hline DXA & $16 \cdot 4$ & $4 \cdot 1$ & $7 \cdot 5-24 \cdot 6$ & $43 \cdot 7$ & $3 \cdot 3$ & $36 \cdot 2-49 \cdot 9$ \\
\hline Difference & Bias & Error & Range & Bias & Error & Range \\
\hline $2 C-4 C$ & -0.9 & $2 \cdot 2$ & $-5 \cdot 4-4 \cdot 1$ & 0.4 & $1 \cdot 1$ & $-2 \cdot 2-2 \cdot 6$ \\
\hline DXA-4C & $-1 \cdot 9^{*}$ & $2 \cdot 6$ & $-6 \cdot 7-6 \cdot 8$ & $1 \cdot 0^{*}$ & 1.4 & $-3 \cdot 7-3.2$ \\
\hline DXA-2C & -1.0 & 3.0 & $-7 \cdot 3-4 \cdot 1$ & 0.5 & 1.5 & $-2 \cdot 0-3 \cdot 9$ \\
\hline
\end{tabular}

Bias, mean difference; error, SD of mean difference.

* Value was significantly different from zero, $P<0.05$.

$\dagger$ For details of subjects, see p. 440 and Table 1.

$\ddagger$ For details of procedures, see p. 441.

population. However, since ballet dancers had a low BMI, a high TBMD was unexpected. The relatively high TBMD was in contrast to Young et al. (1994) and Karlsson et al. (1993), who found no significant differences in TBMD between female ballet dancers and controls. The fact that some studies showed similar TBMD compared with controls, instead of higher TBMD (present study), may be caused by differences in hormonal or menstrual status of the dancers (e.g. all dancers in the study of Young et al. (1994) had delayed menarche and/or secondary menstrual disturbances).

Bone density increases at sites of maximum stress (Wolman et al. 1991; Carter \& Orr, 1992). We found the highest BMD, compared with the reference population, in legs and spines, while the BMD of the arms was not different from that of the reference population. These site-specific differences in BMD of weight-bearing sites between dancers and controls were not found in some other studies in ballet dancers (Frusztajer et al. 1990; Wolman et al. 1991). However, it has been shown also that after controlling for body mass (as a covariate) weight-bearing sites were higher for BMD of ballet dancers compared with those for controls (Karlsson et al. 1993; Young et al. 1994).

Although some studies find relationships between physical activity and BMD, others do not (Sowers \& Galuska, 1993). This could be due to the fact that present physical activity is measured, while the history of physical activity should be taken into account (Sowers \& Galuska, 1993). Surprisingly, in our study there were no relationships between training history and BMD. This does not mean that no relationship exists, but probably illustrates problems in quantifying the history of physical activity. In the present study the effect of physical activity, i.e. period of training (h), on BMD was evident in the legs, the most weight-bearing site in the female ballet dancers studied. Gain in bone mass may occur in healthy young women up to the age of 30 years (Recker et al. 1992). The fact that most dancers in the present study were relatively young and still at an age of bone gain may be the reason that the period of training (h) (reflecting current physical activity) was related to BMD of the legs. Despite some exceptions (McCulloch et al. 1990; Mazess \& Barden, 1991), other studies have also found relationships between current physical activity and BMD (Aloia et al. 1988).

The age of menarche in ballet dancers (median 14.0 years, 90 th percentile 16.2 years) was higher than the age of menarche of the general population in the Netherlands (median 13.3 

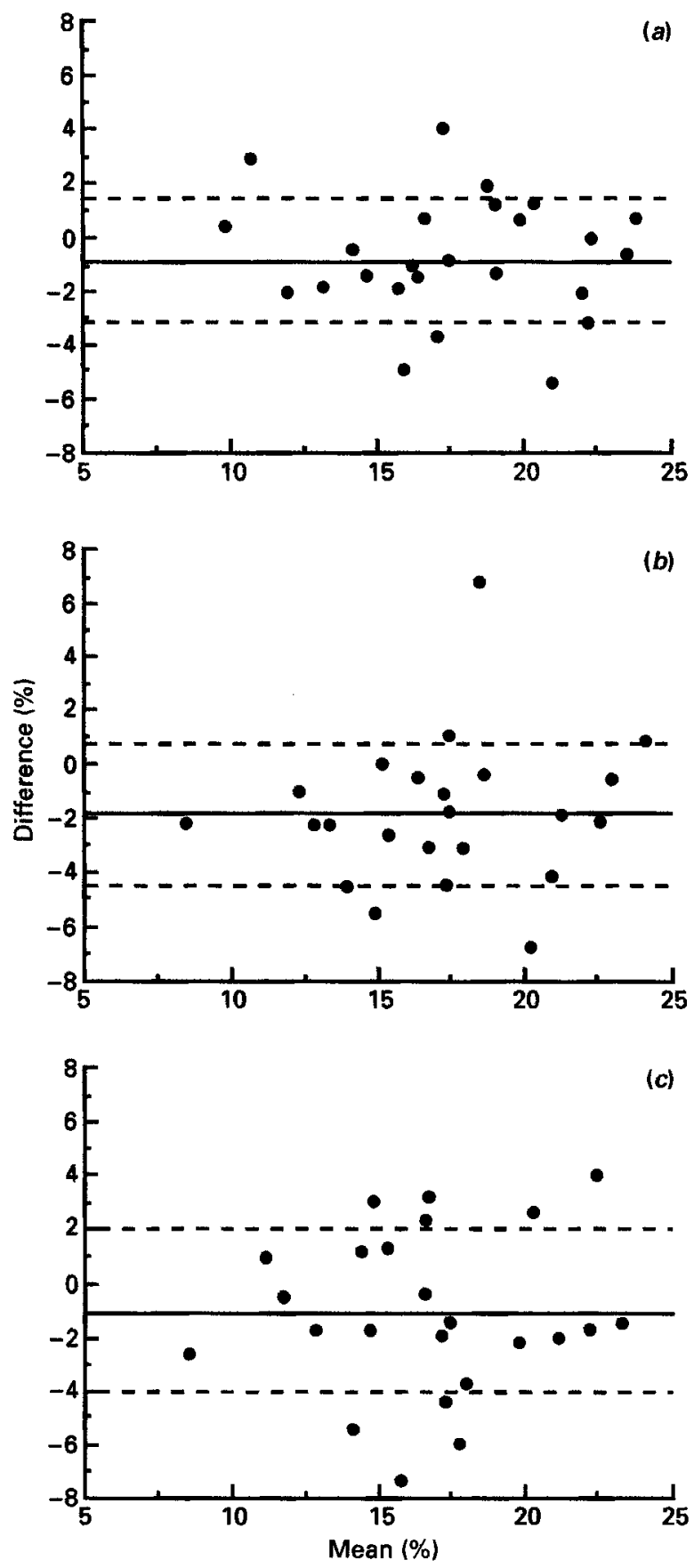

Fig. 3. Differences between percentage body fat of twenty-four female ballet dancers derived from 2-component (2C) and 4-component (4C) models and dual-energy X-ray absorptiometry plotted against the mean value for the two sets of measurements: (a) 2C and 4C, (b) DXA and 4C, (c) DXA and 2C. (O), Individual differences between methods; (-), relative bias; (--), SD of mean differences; for details, see Table 5 . For details of subjects and procedures, see pp. $440-441$ and Table 1 . 
years, 90th percentile 14.9 years; Roede \& Wieringen, 1985). This is in agreement with earlier studies, where ballet dancers start menses later compared with the general population (Warren, 1980; Holderness et al. 1994). Our study showed that BMD and age of menarche were inversely related. This confirms results from earlier studies where late age of menarche was related to low spine BMD (Rosenthal et al. 1989), lower baseline radial BMD (Sowers et al. 1992a), and scoliosis (Warren et al. 1986a, b). Possible explanations are: bone mineralization may be stimulated earlier in women with early menstruation due to an oestrogen surge after initiation of menses (Jaffe \& Dell'Aqua, 1985; Sowers \& Galuska, 1993), or delayed menarche is indicative of inadequate hormone levels during adolescence (Rosenthal et al. 1989). We did not find a relationship between training history and age of menarche so that a common cause related to ballet training or BMD was not evident. On the other hand, age of menarche was negatively related to BMI, suggesting that body mass was a covariate. Since ballet is associated with low dietary intake, and low energy intake during childhood and early adolescence may influence the age of menarche (Warren, 1980), diet could be the common cause related to menarche and BMD.

We could not find any relationship between $\mathrm{Ca}$ intake and BMD. Many other studies were unable to show a relationship with current or childhood $\mathrm{Ca}$ intake (Aloia et al. 1988; Kanders et al. 1988; McCulloch et al. 1990; Heinonen et al. 1993). Some studies, however, have found an effect of Ca intake on BMD (Halioua \& Anderson, 1989) or of Ca intake on bone mass gain (Recker et al. 1992). A possible explanation for these divergent findings is that there is no association between $\mathrm{Ca}$ intake and bone density if $\mathrm{Ca}$ intake is above a certain threshold (800-1000 mg; Kanders et al. 1988). In our study, however, there was not a relationship between $\mathrm{BMD}$ and $\mathrm{Ca}$ intake in those ballerinas that consumed less than $800 \mathrm{mg} / \mathrm{d}$. It could be that the group was too small and heterogeneous to find such a relationship. Another reason could be under-reporting. Because the reported energy intake was only $16 \%$ higher than the measured RMR, it is very likely that intake was underreported. Thus, actual $\mathrm{Ca}$ intake was probably higher and may have surpassed the previously mentioned threshold.

\section{Method comparison}

With respect to the hydration of the FFM, the $4 \mathrm{C}$ model should not deviate from the $2 \mathrm{C}$ model. However, TBMD was high in dancers compared with that of the reference population and, thus, may affect the composition of the FFM. We did find a significant relationship between the difference in percentage body fat, determined by the $2 \mathrm{C}$ and $4 \mathrm{C}$ models, and TBMD. The average difference, however, was not statistically significant. Thus, the impact of the relatively high BMD in the dancers on body fat assessment by the $2 \mathrm{C}$ model was on average modest. However, in those dancers with very high or low BMD the $4 \mathrm{C}$ model will be more accurate, or the $2 \mathrm{C}$ model will require adjustments in the equations used to convert $D_{b}$ to percentage body fat.

We also found significant relationships between percentage body fat differences between DXA and the component models. In general our DXA results for percentage body fat were similar to those derived by UWW, but significantly lower than those derived by the $4 \mathrm{C}$ model. Some studies reported an underestimate of the percentage body fat estimated by DXA compared with that by UWW (Fuller et al. 1992; Johansson et al. 1993), some found similar results (Van Loan \& Matclin, 1992), while others found higher percentage body fat values with DXA (Pritchard et al. 1993). Snead et al. (1993) showed that differences in percentage body fat values between UWW and DXA methods increased with age and BMD and percentage body fat, and that DXA may underestimate percentage body fat in the trunk region. Others have shown that differences in percentage body fat could be attributed to the instrument used (Pritchard et al. 1993). Given the dissimilarities in values 
from the different studies, the influence of BMD on the UWW results, and the instrument and software dependence of the DXA results, it is preferable to use the $4 \mathrm{C}$ model to assess body composition when accurate measurements are needed.

\section{Conclusion}

The present study showed that, despite the factors that have a negative effect on BMD, such as low body mass and late menarche, BMD in female ballet dancers was relatively high. These high values were probably caused by high levels of weight-bearing physical activity.

The authors thank the ballet companies and academies that made this study possible; the Department of Nuclear Medicine of the Academic Hospital in Maastricht for use of the dual-energy X-ray absorptiometry apparatus; and Loek Wouters who performed the ${ }^{2} \mathrm{H}$ analyses.

\section{REFERENCES}

Aloia, J. F., Vaswani, A. N., Yeh, J. K. \& Cohn, S. H. (1988). Premenopausal bone mass is related to physical activity. Archives of Internal Medicine 148, 121-123.

Altman, D. G. \& Bland, J. M. (1983). Measurement in medicine: the analysis of method comparison studies. The Statistician 32, 307-317.

American Psychiatric Association (1987). Diagnostic and Statistical Manual of Mental Disorders. Washington, DC: American Psychiatric Association.

Biller, B. M. K., Saxe, V., Herzog, D. B., Rozenthal, D. I., Holzman, S. \& Klibanski, A. (1989). Mechanisms of osteoporosis in adult adolescent women with anorexia nervosa. Journal of Clinical Endocrinology and Metabolism 68, 548-554.

Carter, D. R. \& Orr, T. E. (1992). Skeletal development and bone functional adaptation. Journal of Bone Mineral Research 7, \$389-\$395.

Clarkson, P. M., Freedson, P. S., Keller, B., Carney, D. \& Skrinar, M. (1985). Maximal oxygen uptake, nutritional patterns, and body composition of adolescent female ballet dancers. Research Quarterly for Exercise and Sport 56, 180-184.

Deurenberg, P., Weststrate, J. A. \& Seidell, J. C. (1991). Body mass index as a measure of body fatness: age- and sex-specific prediction formulas. British Journal of Nutrition 65, 105-114.

Dixon, W. J. (1950). Analyses of extreme values. Annals of Mathematical Statistics 21, 488-506.

Frusztajer, N. T., Dhuper, S., Warren, M. P., Brooks, G. J. \& Fox, R. P. (1990). Nutrition and the incidence of stress fractures in ballet dancers. American Journal of Clinical Nutrition 51, 779-783.

Fuller, N. J., Laskey, M. A. \& Elia, M. (1992). Assessment of the composition of major body regions by dualenergy X-ray absorptiometry (DEXA), with special reference to limb muscle mass. Clinical Physiology 12 , 253-266.

Halioua, L. \& Anderson, J. J. (1989). Lifetime calcium intake and physical activity habits: independent and combined effects on the radial bone of healthy premenopausal Caucasian women. American Journal of Clinical Nutrition 49, 534-541.

Heinonen, A., Oja, P., Kannus, P., Sievanen, H., Manttari, A. \& Vuori, I. (1993). Bone mineral density of female athletes in different sports. Bone and Mineral 23, 1-14.

Hergenroeder, A. C., Fiorotto, M. L. \& Klish, W. J. (1991). Body composition in ballet dancers measured by total body electrical conductivity. Medicine Science Sports and Exercise 23, 528-533.

Holderness, C. C., Brooks, G. J. \& Warren, M. P. (1994). Eating disorders and substance use: a dancing vs a nondancing population. Medicine Science Sports and Exercise 26, 297-302.

Jaffe, R. B. \& Dell'Aqua, S. (1985). The Endocrine Physiology of Pregnancy and the Peripartal Period. New York: Raven Press.

Johansson, A. G., Forslund, A., Sjodin, A., Mallmin, H., Hambraeus, L. \& Ljunghall, S. (1993). Determination of body composition - a comparison of dual-energy X-ray absorptiometry and hydrodensitometry. American Journal of Clinical Nutrition 57, 323-326.

Kanders, B., Dempster, D. W. \& Lindsay, R. (1988). Interaction of calcium nutrition and physical activity on bone mass in young women. Journal of Bone Mineral Research 3, $145-149$.

Karlsson, M. K., Johnell, O. \& Obrant, K. J. (1993). Bone mineral density in professional ballet dancers. Bone and Mineral 21, 163-169.

Kirkendall, D. T. \& Calabrese, L. H. (1983). Physiological aspects of dance. Clinics in Sports Medicine 2, $525-537$. Kommissie UCV (1994). Uitgebreide voedingsmiddelen tabel. Den Haag: Voorlichtingsbureau voor de voeding. Lohman, T. G. (1992). Advances in Body Composition Assessment. Champaign, Ill.: Human Kinetics Publishers. Lunar Corporation (1993). DPX-L Software Version 1.3z. Medicine, Wis.: Lunar Corporation.

McCulloch, R. G., Bailey, D. A., Houston, C. S. \& Dodd, B. L. (1990). Effects of physical activity, dietary calcium 
intake and selected lifestyle factors on bone density in young women. Canadian Medical Association Journal 142, 221-227.

Mazess, R. B. \& Barden, H. S. (1991). Bone density in premenopausal women: effects of age, dietary intake, physical activity, smoking, and birth-control pills. American Journal of Clinical Nutrition 53, 132-142.

Mazess, R. B., Barden, H. S., Bisek, J. P. \& Hanson, J. (1990). Dual-energy X-ray absorptiometry for total-body and regional bone-mineral and soft-tissue composition. American Journal of Clinical Nutrition 51, 1106-1112.

Miller, M. E., Cosgriff, J. M. \& Forbes, G. B. (1989). Bromide space determination using anion-exchange chromatography for measurement of bromide. American Journal of Clinical Nutrition 50, 168-171.

Pritchard, J. E., Nowson, C. A., Strauss, B. J., Carlson, J. S., Kaymakci, B. \& Wark, J. D. (1993). Evaluation of dual energy X-ray absorptiometry as a method of measurement of body fat. European Journal of Clinical Nutrition 47, $216-228$.

Recker, R. R., Davies, K. M., Hinders, S. M., Heaney, R. P., Stegman, M. R. \& Kimmel, D. B. (1992). Bone gain in young adult women. Journal of the American Medical Association 268, 2403-2408.

Rigotti, N. A., Nussbaum, S. R, Herzog, D. B. \& Neer, R. M. (1984). Osteoporosis in women with anorexia nervosa. New England Journal of Medicine 311, 1601-1606.

Risser, W. L., Lee, E. J., LeBlanc, A., Poindexter, H. B., Risser, J. M. \& Schneider, V. (1990). Bone density in eumenorrheic female college athletes. Medicine Science Sports and Exercise 22, 570-574.

Roede, M. J. \& Wieringen, J. C. v. (1985). Growth diagrams 1980 . Netherlands third nation-wide survey. Tijdschrift voor sociale gezondheidszorg Suppl. 1985, 1-34.

Rosenthal, D. I., Mayo, S. W., Hayes, C. W., Khurana, J. S., Biller, B. M., Neer, R. M. \& Klibanski, A. (1989). Age and bone mass in premenopausal women. Journal of Bone Mineral Research 4, 533-538.

Schoeller, D. A., Van Santen, E., Peterson, D. W., Dietz, W., Jaspen, J. \& Klein, P. (1980). Total body water measurements in humans with ${ }^{18} \mathrm{O}$ and ${ }^{2} \mathrm{H}$ labelled water. American Journal of Clinical Nutrition 33, $2686-2693$.

Shizgal, H. M. (1983). Body composition. Surgical Nutrition, pp. 3-17. Boston: Little, Brown and Co.

Siri, W. E. (1956). The gross composition of the body. Advances in Biological and Medical Physics 4, $239-280$.

Snead, D. B., Birge, S. J. \& Kohrt, W. M. (1993). Age-related differences in body composition by hydrodensitometry and dual-energy X-ray absorptiometry. Journal of Applied Physiology 74, 770-775.

Sowers, M. \& Galuska, D. (1993). Epidemiology of bone mass in premenopausal women. Epidemiological Review 15, 374-398.

Sowers, M. R., Clark, M. K., Hollis, B., Wallace, R. B. \& Jannausch, M. (1992a), Radial bone mineral density in pre- and perimenopausal women: a prospective study of rates and risk factors for loss. Journal of Bone Mineral Research 7, 647-657.

Sowers, M. R., Kshirsagar, A., Crutchfield, M. M. \& Updike, S. (1992b). Joint influence of fat and lean body composition compartments on femoral bone mineral density in premenopausal women. American Journal of Epidemiology 136, 257-265.

Suominen, H. (1993). Bone mineral density and long term exercise. An overview of cross-sectional athlete studies. Sports Medicine 16, 316-330.

Van Loan, M. D. \& Matclin, P. L. (1992). Body composition assessment: dual-energy X-ray absorptiometry (DEXA) compared to reference methods. European Journal of Clinical Nutrition 46, 125-130.

Warren, M. P. (1980). The effects of exercise on pubertal progression and reproductive function in girls. Journal of Clinical Endocrinology and Metabolism 51, 1150-1157.

Warren, M. P., Brooks, G. J., Fox, R. P., Lancelot, C., Newman, D. \& Hamilton, W. G. (1991). Lack of bone accretion and amenorrhea: evidence for a relative osteopenia in weight-bearing bones. Journal of Clinical Endocrinology and Metabolism 72, 847-853.

Warren, M. P., Brooks, G. J., Hamilton, L. H., Warren, L. F. \& Hamilton, W. G. (1986a). Scoliosis and fractures in young ballet dancers. Relation to delayed menarche and secondary amenorrhea. New England Journal of Medicine 314, 1348-1353.

Warren, M. P., Brooks, G. J., Hamilton, L. H., Warren, L. F. \& Hamilton, W. G. (1986b). Scoliosis and fractures in young ballet dancers. Relation to delayed menarche and secondary amenorrhea (Erratum). New England Journal of Medicine 315, 905.

Weir, J. B. (1949). New methods for calculating metabolic rate with special reference to protein metabolism. Journal of Physiology 109, 1-9.

Westerterp, K. R., Meijer, G. A. L., Kester, A. D. M., Wouters, L. \& ten Hoor, F. (1992). Fat-free mass as a function of fat mass and habitual activity level. International Journal of Sports Medicine 13, $163-166$.

Withers, R. T., Smith, D. A., Chatterton, B. E., Schultz, C. G. \& Gaffney, R. D. (1992). A comparison of four methods of estimating the body composition of male endurance athletes. European Journal of Clinical Nutrition 46, 773-784.

Wolman, R. L., Faulman, L., Clark, P., Hesp, R. \& Harries, M. G. (1991). Different training patterns and bone mineral density of the femoral shaft in elite, female athletes. Annals of the Rheumatic Diseases 50, 487-489.

Young, N., Formica, C., Szmukler, G. \& Seeman, E. (1994). Bone density at weight-bearing and nonweightbearing sites in ballet dancers: the effects of exercise, hypogonadism, and body weight. Journal of Clinical Endocrinology and Metabolism 78, 449-454. 